\title{
Divulgação Voluntária da Cadeia de Valor nos Relatórios Financeiros de Empresas Brasileiras de Capital Aberto
}

\author{
Voluntary disclosure of Value Chain in Financial Reports of Companies Brazilian \\ Capital Open
}

\author{
Leandro da Costa Lopes \\ Mestrando em Ciências Contábeis - UFPE \\ Discente do Programa de Pós-Graduação em Ciências Contábeis da UFPE \\ Rua Itaborá, 119 Vasco da Gama, Recife/PE, CEP: 52081-083 \\ leandro.85@hotmail.com \\ Juliana Matos de Meira \\ Ph.D. em Management - University of Sheffield \\ Professora Adjunta do Departamento de Ciências Contábeis e Atuariais da UFPE \\ Av. dos Economistas, s/n Cidade Universitária, Recife/PE, CEP: 50670-901 \\ j.meira@hotmail.co.uk \\ Luiz Carlos Miranda \\ Ph.D. Program In Agribusiness - University of Illinois \\ Professor Titular do Departamento de Ciências Contábeis e Atuariais da UFPE \\ Av. dos Economistas, s/n Cidade Universitária, Recife/PE, CEP: 50670-901 \\ lc-miranda@uol.com.br \\ Marco Tullio de Castro Vasconcelos \\ Doutor em Controladoria e Contabilidade - FEA/USP \\ Professor Adjunto do Departamento de Ciências Contábeis e Atuariais da UFPE \\ Av. dos Economistas, s/n Cidade Universitária, Recife/PE, CEP: 50670-901 \\ mtullio2@gmail.com \\ Aldemar Araújo dos Santos \\ Doutor em Tecnologias e Sistemas de Informação - Universidade do Minho \\ Professor Adjunto do Departamento de Ciências Contábeis e Atuariais da UFPE \\ Av. dos Economistas, s/n Cidade Universitária, Recife/PE, CEP: 50670-901 \\ aldemar@ufpe.br
}

\section{Resumo}

As empresas têm buscado gerenciar a cadeia de valor com o objetivo de obter vantagem competitiva diante de concorrentes e reduzir custos de produção. O objetivo desta pesquisa foi verificar se empresas brasileiras, listadas na Bolsa de Valores de São Paulo (Bovespa), divulgam informações de gerenciamento da cadeia de valor em seus relatórios financeiros, e se existe relação entre a divulgação de tais informações e duas variáveis independentes, Margem Bruta e número de páginas. Foi aplicada a técnica de Análise de Conteúdo nos relatórios da administração e notas explicativas do exercício de 2011, orientada por uma adaptação do instrumento de análise da gestão estratégica de custos elaborado por Wrubel et al. (2010). A amostra selecionada contou com as dez maiores empresas brasileiras, não

Artigo publicado anteriormente nos Anais do VI Seminário UFPE de Ciências Contábeis em 2012.

Artigo submetido em 01 de novembro de 2012 e aceito em 28 de dezembro de 2012 pelo Editor Marcelo Alvaro da Silva Macedo, após double blind review. 
financeiras, adotando-se o critério de maior ativo total registrado. Embora a divulgação desse tipo de informação não seja de natureza obrigatória, constata-se que as empresas analisadas apresentaram em média 30 sentenças relacionadas ao tema em seus relatórios. A subcategoria de atividades da cadeia de valor interna e externa representa $54,58 \%$ do total de sentenças identificadas. Verificou-se que existe correlação positiva significativa entre a quantidade de sentenças divulgadas e o número de páginas dos relatórios, porém, verificou-se que o mesmo não ocorre quando tentou-se correlacionar com a margem bruta, não sendo possível afirmar que maior margem bruta incentivaria um volume maior de divulgação de informações da cadeia de valor.

Palavras-chave: Cadeia de Valor. Divulgação Voluntária. Vantagem Competitiva. Custos de Produção.

\begin{abstract}
Managing the value chain with the aim to achieve competitive advantage in relation to their competitors and in order to reduce costs has become increasingly important for business organizations. The aim of this paper is to analyse whether Brazilian organisations listed on Sao Paulo's Stock Exchange (BOVESPA) publish information relating to value chain management in their financial reports. In addition, this research aims to investigate the potential relationtionship between evidentiation of this information and two independent variables, gross margin and number of pages. Content Analysis was adopted in the management report and report notes of the year 2011. The analysis was based on the strategic cost management framework developed by Wrubel et al. (2010). The sample selected includes the ten largest non financial organizations, according to their total assets. Despite the fact that publishing the value chain management is not compulsory, it was observed that the businesses studied present on average 30 sentences regarding the topic in their reports. The category internal and external value chain activities represents $54.58 \%$ of the total sentences found. It has been found that there is a significant positive correlation between the amount of sentences disclosed and page number of reports, however, it was found that the same does not occur when attempted to correlate the gross margin. As a consequence, the hypothesis that gross margin could be a motivation for higher volume of information regarding value chain was not confirmed.
\end{abstract}

Keywords: Value Chain. Volunteer Publishing. Competitive Advantage. Production costs.

\title{
1. Introdução
}

Para que um produto chegue às mãos do cliente final ele atravessa várias etapas que compõem o processo produtivo e geram valor para esse produto (SHANK e GOVINDARAJAN, 1997). Na confecção de um único produto existem várias etapas que seguem uma ordem até a sua conclusão e que na maioria das vezes não será desenvolvida por uma única empresa, mas, em uma visão ampla, em conjunto com outras que são responsáveis por cada parte do processo.

Com o tempo, os gestores passaram a observar que para as empresas obterem melhores vantagens competitivas eles precisariam fazer o gerenciamento não apenas de suas atividades e processos internos (geração de valor horizontal), mas de todo o processo de confecção (geração de valor horizontal e vertical), denominada cadeia de valor.

$\mathrm{O}$ gerenciamento da cadeia de valor vem ganhando espaço nas discussões, tanto nas empresas como na academia, tema recorrente na prática de gestão adotada por grandes empresas e em pesquisas acadêmicas (ROCHA e BORINELLI, 2007). Porém, há poucas 
pesquisas que visam identificar se as empresas divulgam em seus relatórios externos as ações e medidas adotadas na cadeia e os fatores que determinam essa divulgação.

Hendriksen e Van Breda (1999) em relação à divulgação de informações, afirmam que embora haja um julgamento intuitivo do que seja apropriado divulgar, não há evidências que permitam determinar o que seja apropriado divulgar nos relatórios financeiros das empresas. Dessa forma, torna-se mais prático e menos trabalhoso para as empresas divulgar apenas o que é determinado em normas. Contudo, a prática de divulgação de informações financeiras e gerenciais que visem proporcionar um melhor entendimento das ações da empresa para o investidor, além das que são obrigatórias por força de normatização, é estimulada pelos órgãos que emitem as normas brasileiras de contabilidade, pelos órgãos reguladores e profissionais de auditoria.

Um ponto relevante levantado por Elmuti (2002) questiona que fatores estão associados com o sucesso ou fracasso dos programas de gerenciamento de cadeia de valor. A partir desse entendimento, considerando a problemática destacada e após a observação de diversas pesquisas relacionadas ao tema, mas que não abordam sua divulgação voluntária e explicações, tomou-se como objetivo verificar se as empresas divulgam informações sobre o gerenciamento da cadeia de valor de relatórios e se existe relação com a Margem Bruta e o número de páginas destes.

Considerando que o gerenciamento da cadeia de valor proporciona diferencial para a empresa, pois pode gerar a redução de custos e diferenciais ao produto final para seus clientes que podem alavancar suas vendas, acredita-se que as empresas que fazem o seu gerenciamento podem obter maior margem bruta que aquelas que não adotam essa prática, e que a empresa pode julgar importante mostrar as ações que está implementando para melhorar seus resultados. Por outro lado, acredita-se que quanto mais informações forem disponibilizadas para os usuários dos relatórios, maior será o interesse desses pela empresa.

Este estudo apresenta uma revisão da literatura abordando o gerenciamento da cadeia de valor, a prática de divulgação voluntária de informações em relatórios financeiros e estudos anteriores relacionados ao tema proposto. Será abordada a construção da metodologia proposta para a consecução dos objetivos propostos, e uma análise descritiva dos dados. A última seção apresentará a conclusão do estudo com base nos resultados encontrados, sua limitação de interpretação e sugestões para pesquisas futuras.

\section{Fundamentação Teórica}

\subsection{Gestão da Cadeia de Valor}

De acordo com Rocha e Borinelli (2007), partindo-se do pressuposto que as atividades devem ser o foco da gestão para se conquistar e conservar vantagens competitivas, e sabendose que elas são executadas em sequência lógica, formando uma cadeia, chega-se à ideia de cadeia de valor. A cadeia de valor é constituída de processos e atividades estratégicas distintas de um mesmo setor, que podem ser identificadas como geradoras de valores e a esses possam ser atribuídos custos, receitas e ativos necessários ao processo (SHANK e GOVINDARAJAN, 1997). No processo que compreende desde a extração da matéria-prima para a produção de um item até a sua entrega ao consumidor final, representa a cadeia de valor, e cada atividade desenvolvida deve ser gerenciada.

Para Porter (1980), uma empresa pode obter dentro de sua cadeia de valor, vantagem competitiva com base na redução de custos ou na diferenciação do produto que é ofertado ao consumidor, como pode também conseguir vantagens de ambas as formas. Para que essas vantagens possam ser obtidas, segundo Shank e Govindarajan (1997), dependerá da maneira 
como a empresa fará o gerenciamento de sua cadeia de valor em comparação com as cadeias de valor de seus concorrentes.

Para Mentzer et al. (2001), as empresas que praticam a gestão da cadeia de valor buscam vantagens competitivas no mercado, redução de custos e melhoria na satisfação do cliente. O que diferencia essa prática das demais é que as empresas não procuram alcançar redução de custos ou melhoria de lucro às em relação a seus parceiros da cadeia de valor, mas sim procuram tornar a cadeia mais competitiva e a maximização dos resultados ao longo da cadeia (LI e CHEN, 2001; COOPER et al., 1997). Tendo em vista as vantagens proporcionadas pelo gerenciamento da cadeia de valor para as empresas, Shank e Govindarajan (1997) afirmam que os gestores que tomam por objetivos de sua gestão não apenas reduzir os custos e otimizar a eficiência, mas desejam agregar valor aos produtos e serviços oferecidos aos clientes, necessitam analisar a cadeia de valor para identificar oportunidades de melhoria.

\subsection{Divulgação nos relatórios financeiros}

Segundo Bravo, Abad e Trombetta (2008), os relatórios financeiros emitidos pela contabilidade são a principal forma de disclosure das informações corporativas. Tomando por base esta afirmativa pode-se considerar que os relatórios financeiros publicados pelas empresas devem conter informações que permitam aos seus usuários o conhecimento das ações desenvolvidas e fatores relacionados aos resultados alcançados.

Como forma de orientar as empresas quanto ao que se devem divulgar nos relatórios financeiros, os órgãos reguladores profissionais e das empresas destacam alguns pontos que necessitam de informações adicionais e estabelece que sejam divulgados em notas. Porém, a empresa também é incentivada a divulgar informações voluntárias que visem permitir esclarecer o que está divulgando e os resultados obtidos.

As empresas ainda têm muito que evoluir no sentido da transparência e qualidade da divulgação voluntária de informação (COLARES e PONTES, 2003). Por não haver direcionadores de atenção para o que se deve informar aos investidores, cabe ao gestor realizar o julgamento do que deve ou não divulgar e quais benefícios serão proporcionados pelo maior grau de disclosure.

A divulgação de informações não obrigatórias nos relatórios de informações financeiras pode ser explicada por diversas características da própria empresa e por sua expectativa de interpretação dos usuários da informação (CUNHA e RIBEIRO, 2006). Nessa perspectiva pode-se considerar que, embora o julgamento dos gestores do que se deve divulgar voluntariamente dependa de questões internas, pode ocorrer em diversas empresas. Segundo Healy e Palepu (2000), a divulgação de informações é um fator fundamental para o correto funcionamento do mercado de capitais e por isso merece a atenção dos pesquisadores e das empresas. Portanto, pode-se acreditar que as informações que são divulgadas pelas empresas abertas que negociam suas ações em mercado tendem a evidenciar informações que julguem importantes para atrair investidores.

\subsection{Estudos da cadeia de valor nos relatórios financeiros}

Um estudo realizado por Wrubel, Diehl e Ott (2010) verificou a divulgação sobre a gestão estratégica de custos por companhias abertas brasileiras, analisando 30 relatórios divulgados entre os anos de 2005 e 2007, selecionados aleatoriamente. Para a coleta dos dados os autores elaboraram um instrumento que categorizou termos relacionados ao tema a partir do método Delphi, que incluiu análise da cadeia de valor, análise de direcionadores de custos e análise do posicionamento estratégico. 
Dentre os resultados da pesquisa, ficou constatado que 47,2\% dos relatórios analisados divulgavam informações relacionadas às categorias associadas à Análise da Cadeia de Valor, recebendo destaque a identificação da cadeia de valor à qual pertenciam, seus principais clientes e fornecedores e informações sobre contratos de fornecimento de produtos ou serviços. Os autores constataram que não havia relação significativa entre a divulgação e o tamanho da empresa ou seu nível de governança corporativa registrado na Bovespa.

Rocha e Borinelli (2007) realizaram um estudo exploratório da lucratividade de 10 grandes empresas que compõem a cadeia de valor da indústria de bens de consumo e das grandes redes de supermercados que atuam no Brasil. Através do qual foi possível constatar que não houve um aumento na margem bruta das empresas que atuam no varejo em detrimento do crescimento da mesma margem nas indústrias de bens de consumo. Os autores destacaram ainda que a margem bruta das indústrias de bens de consumo manteve-se estável ou aumentou em proporção mais elevada que as empresas do varejo, comparando-se os relatórios financeiros dos exercícios encerrados em 2000 e 2004 observados nesse estudo.

\section{Metodologia da Pesquisa}

O universo desta pesquisa são as empresas brasileiras de capital aberto que negociam seus títulos na Bolsa de Valores de São Paulo (Bovespa) e que publicaram suas demonstrações contábeis do exercício de 2011. A amostra foi selecionada por julgamento dos autores, considerando o porte e a relevância para a economia de mercado, composta pelas 10 empresas que possuem os maiores valores de ativo total registrados em seus balanços.

As empresas selecionadas têm suas atividades concentradas nos seguintes setores: Petróleo e Gás, Mineração, Energia elétrica, Alimentos e bebidas, Siderurgia e Metalurgia, Telecomunicações, Química. Devido à especificidade da pesquisa, foram excluídas da amostra empresas que atuam no setor financeiro. No Quadro 1 são apresentadas as empresas, por ordem decrescente de tamanho de ativo total, que compõem a amostra.

\section{Quadro 1: Amostra da pesquisa}

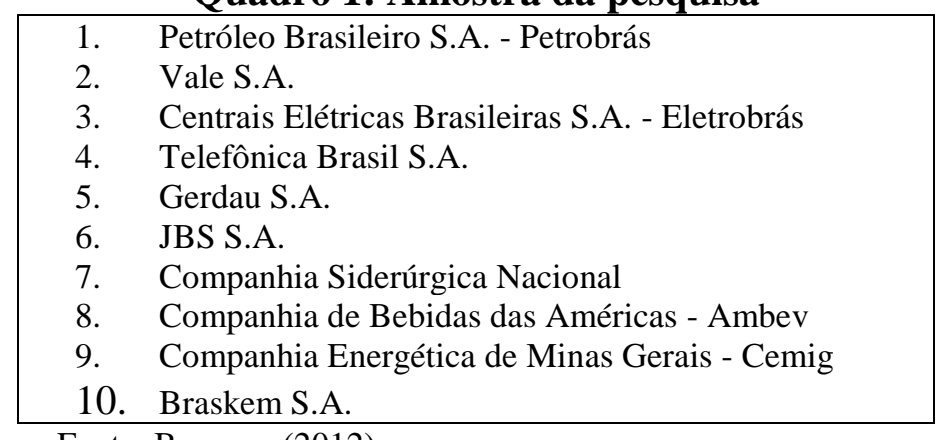

Fonte: Bovespa (2012)

Os documentos considerados na análise dos dados foram os que compõem o sentido mais estrito de divulgação financeira destacado por Hendriksen e Van Breda (1997), que inclui o Relatório Anual da Administração, Notas Explicativas das Demonstrações Financeiras Padronizadas (DFP), quadros e demonstrativos complementares que tenham sido publicados no sítio eletrônico da Bovespa ou das próprias empresas estudadas.

O instrumento utilizado para a coleta de dados nos relatórios de divulgação financeira foi elaborado a partir de uma adaptação do elaborado por Wrubel, Diehl e Ott (2010), que categorizou termos relacionados à gestão estratégica de custos. Como o foco desta pesquisa é a Cadeia de Valor, foram descartados do instrumento os termos relacionados aos 
direcionadores de custos e ao posicionamento estratégico, restringindo ao foco deste estudo (Quadro 2).

\section{Quadro 2: Categorias da Análise da Cadeia de Valor}

\begin{tabular}{|c|c|}
\hline \multicolumn{2}{|c|}{ Análise da Cadeia de Valor } \\
\hline $\begin{array}{l}\text { Elos/Etapas/Atividades da cadeia de valor interna e } \\
\text { externa }\end{array}$ & $\begin{array}{l}\text { Poder de negociação dos fornecedores (cadeia } \\
\text { de suprimento) }\end{array}$ \\
\hline Identificação da cadeia de valor & Atividades dos clientes (cadeia de distribuição) \\
\hline Integração vertical & Visão de todo o negócio ou visão sistêmica \\
\hline $\begin{array}{l}\text { Atividades, compromissos ou exigências } \\
\text { fornecedores (cadeia de suprimento) }\end{array}$ & Ciclo de vida útil do produto/serviço \\
\hline
\end{tabular}

Fonte: Adaptado de Wrubel, Diehl e Ott (2010).

A técnica utilizada foi a de Análise de Conteúdo, que segundo Bardin (2011) utiliza procedimentos sistemáticos e objetivos para análise das comunicações em texto, visando descrever e classificar o conteúdo das mensagens analisadas. A adoção deste método justificase em razão das informações relacionadas a cada subcategoria estarem dispostas em formato de texto nos relatórios financeiros, sendo em seguida tratados de forma quantitativa, tendo em vista que o foco desta pesquisa é destacar e buscar correlações entre o volume de informações da cadeia de valor divulgadas por cada empresa analisada e duas variáveis independentes, Margem Bruta e número de páginas dos relatórios.

Para a obtenção da variável Margem Bruta relacionada neste estudo, foi utilizado o software Economática com o objetivo de obter informações mais precisas para cada empresa em 2011. Para cálculo das correlações entre as variáveis e criação dos gráficos que compõem a análise dos dados foi utilizado o Excel (versão 2007). Após o tratamento dos dados de forma quantitativa e observadas suas possíveis correlações com cada variável, foi realizada a análise descritiva.

\section{Análise dos Dados}

Foram consultados o Relatório da Administração/Comentário de Desempenho e as Notas Explicativas disponíveis no sítio da Bovespa referentes ao exercício de 2011. No primeiro momento da pesquisa observou-se que não há um padrão quanto de estrutura de apresentação do relatório da administração, diferentemente das notas explicativas que seguem estrutura semelhante em todas as empresas consultadas, o que se justifica pela normatização do conteúdo mínimo das notas explicativas determinado pelas Normas Brasileiras de Contabilidade emitidas pelo Conselho Federal de Contabilidade. Observou-se que os relatórios divulgados têm informações relacionadas à cadeia de valor a qual cada empresa pertence, desta forma, transmite ao usuário das informações financeiras divulgadas, conhecimentos de importantes fatores relacionados às atividades que desenvolvem. Isso permite afirmar que embora essas informações não sejam obrigatórias, há uma tendência em publicá-las.

Nesta pesquisa não se avaliou a qualidade das informações divulgadas, apenas se essas informações eram transmitidas por meio dos relatórios financeiros e a frequência com que são apresentadas, independentemente do conteúdo trazer informações positivas, negativas ou perspectivas futuras. Após a realização da análise de conteúdo, foram quantificadas as sentenças divulgadas que apresentam informações ligadas à cadeia de valor. O Quadro 3 mostra as empresas e suas respectivas quantidades de citações, por ordem decrescente, encontradas nos relatórios analisados. 
Quadro 3: Quantidades de sentenças por empresas

\begin{tabular}{|c|c|c|}
\hline Empresa & $\begin{array}{l}\text { Quantidade } \\
\text { de Citações }\end{array}$ & $\begin{array}{l}\text { Percentuais } \\
\text { de Citações }\end{array}$ \\
\hline 1. Companhia Energética de Minas Gerais - Cemig & 58 & 18,95 \\
\hline 2. JBS S.A. & 50 & 16,33 \\
\hline 3. $\quad$ Braskem S.A. & 40 & 13,07 \\
\hline 4. $\quad$ Telefônica Brasil S.A. & 37 & 12,09 \\
\hline 5. Centrais Elétricas Brasileiras S.A. - Eletrobrás & 33 & 10,78 \\
\hline 6. $\quad$ Petróleo Brasileiro S.A. - Petrobrás & 29 & 9,48 \\
\hline 7. Companhia Siderúrgica Nacional & 20 & 6,55 \\
\hline 8. Companhia de Bebidas das Américas - Ambev & 17 & 5,56 \\
\hline 9. $\quad$ Gerdau S.A. & 13 & 4,25 \\
\hline 10. Vale S.A. & 9 & 2,94 \\
\hline Total & 306 & $\mathbf{1 0 0 , 0 0}$ \\
\hline
\end{tabular}

Observa-se que a empresa que mais apresentou citações foi a Companhia Energética de Minas Gerais (Cemig), 58 citações $(18,95 \%)$ das sentenças identificadas na análise, o que mostra preocupação em fornecer informações amplas aos investidores e credores, destinatários principais das informações financeiras divulgadas pelas empresas; a que menos apresentou informações da cadeia de valor foi a Vale, com 9 citações $(2,94 \%)$.

Calculando-se a média de sentenças identificadas nos relatórios, chegou-se a 30 ocorrências, o que permite afirmar que $50 \%$ das empresas analisadas foram ordenadas abaixo desse volume. É importante destacar que todas as empresas que compõem a amostra apresentaram sentenças que se relacionam a cadeia de valor.

$\mathrm{O}$ volume de sentenças identificados neste estudo é um pouco inferior ao encontrado por Wrubel, Diehl e Ott (2010), considerando-se uma proporção para o número de empresas analisados nesta pesquisa. Contudo, a diferença encontrada não permite afirmar que as empresas vêm reduzindo a divulgação das informações da cadeia de valor, pois a metodologia deste estudo foi focada na análise de conteúdo, daí se tem resultados diferentes por considerar o julgamento dos autores na etapa da coleta dos dados.

Em seguida foi realizada uma análise detalhada das sentenças identificadas por empresa, apresentando quais são as subcategorias mais recorrentes nos relatórios (Quadro 4).

Quadro 4: Quantidades de sentenças por subcategorias

\begin{tabular}{|l|r|r|}
\hline \multicolumn{1}{|c|}{ Subcategoria } & $\begin{array}{c}\text { Quantidade de } \\
\text { sentenças }\end{array}$ & $\begin{array}{c}\text { Percentuais de } \\
\text { citações }\end{array}$ \\
\hline Elos/Etapas/Atividades da cadeia de valor interna e externa & 167 & 54,58 \\
\hline Identificação de membros da cadeia de valor & 73 & 23,86 \\
\hline Integração vertical & 33 & 10,78 \\
\hline Atividades, compromissos ou exigências dos fornecedores & 7 & 2,88 \\
\hline Poder de negociação dos fornecedores & 1 & 0,33 \\
\hline Atividades dos clientes & 20 & 6,54 \\
\hline Visão de todo o negócio ou visão sistêmica & 3 & 0,98 \\
\hline Ciclo de vida do produto/serviço & 2 & 0,65 \\
\hline \multicolumn{1}{|c|}{ Total } & $\mathbf{3 0 6}$ & $\mathbf{1 0 0 , 0 0}$ \\
\hline
\end{tabular}

Percebe-se que a maior parte das empresas divulgam as atividades da cadeia de valor, principalmente as atividades internas. Essa divulgação representa $54,58 \%$ de todas as sentenças observadas neste estudo, o que evidencia que as empresas sentem a necessidade de tornar público aos usuários da informação às atividades que desenvolve dentro da cadeia que 
está inserida. A empresa que mais divulgou suas atividades na cadeia de valor foi a Companhia Energética de Minas Gerais (Cemig).

A identificação da cadeia de valor foi à segunda categoria com maior número de sentenças relacionadas, representando $23,85 \%$ do total observado. Na maior parte das informações identificadas citam quem são seus fornecedores, clientes e apresentam características da cadeia de valor a que pertence.

A integralização vertical da cadeia de valor também teve destaque na divulgação das informações nos relatórios financeiros analisados. Algumas empresas afirmam em seus relatórios que atuam no processo de produção, venda e distribuição dos seus produtos aos consumidores finais, abrangendo quase toda a cadeia de valor. Além disso, a JBS foi a empresa que mais apresentou informações de processo de confecção e venda entre empresas do seu grupo, e algumas empresas têm produção voltadas para o mesmo grupo, e atuam em etapas seguintes do processo produtivo dos alimentos que comercializam. Para as subcategorias - Poder de negociação dos fornecedores, Visão de todo o negócio ou visão sistêmica e Ciclo de vida do produto/serviços - representaram apenas $1,96 \%$ das sentenças identificadas.

Foram identificadas 306 sentenças nos 20 relatórios analisados (Relatório da Administração e Notas Explicativas), das quais 58\% foram observadas nos relatórios da administração e o restante, $42 \%$, nas notas explicativas das empresas (Quadro 5).

Quadro 5: Sentenças encontradas por relatórios

\begin{tabular}{|l|r|r|r|}
\hline \multicolumn{1}{|c|}{ Empresa } & \multicolumn{1}{c|}{$\begin{array}{c}\text { Relatório da } \\
\text { Administração }\end{array}$} & $\begin{array}{c}\text { Notas } \\
\text { Explicativas }\end{array}$ & Total \\
\hline Companhia Energética de Minas Gerais - Cemig & 17 & 41 & 58 \\
\hline JBS S.A. & 8 & 42 & 50 \\
\hline Braskem S.A. & 31 & 9 & 40 \\
\hline Telefônica Brasil S.A. & 35 & 2 & 37 \\
\hline Centrais Elétricas Brasileiras S.A. - Eletrobrás & 29 & 4 & 33 \\
\hline Petróleo Brasileiro S.A. - Petrobrás & 18 & 11 & 29 \\
\hline Companhia Siderúrgica Nacional & 15 & 5 & 20 \\
\hline Companhia de Bebidas das Américas - Ambev & 12 & 5 & 17 \\
\hline Gerdau S.A. & 12 & 1 & 13 \\
\hline Vale S.A. & 2 & 7 & 9 \\
\hline
\end{tabular}

A maior parte das empresas analisadas apresenta um maior volume de sentenças nos relatórios da administração, provavelmente pela estrutura do documento ser mais livre de padrões e permitir que a empresa explane mais o seu desempenho e ações. Apenas a Cemig, JBS e Vale apresentaram volume maior de sentenças nas notas explicativas.

Verificando se haveria correlação significativa entre o volume de páginas dos relatórios e o volume de sentenças relacionadas à cadeia de valor, encontrou-se uma correlação de apenas $31,1 \%$. Da mesma forma como o coeficiente de determinação $\left(\mathrm{r}^{2}\right)$ foi de apenas 0,097 ambos influenciados, principalmente, pela empresa JBS que foi a segunda empresa a exibir o maior número de sentenças e, ao mesmo tempo, teve o menor volume de páginas no conjunto dos relatórios analisados.

Realizou-se nova análise de correlação retirando a JBS da amostra. Na segunda observação do comportamento das variáveis encontrou-se uma correlação positiva de $64,71 \%$ e o coeficiente de determinação $\left(\mathrm{r}^{2}\right)$ subiu para 0,4188. Assim, pode-se afirmar que há uma moderada crescente entre as variáveis observadas. Esse achado, embora em valores inferiores, vem corroborar o resultado obtido por Wrubel, Diehl, Ott (2010), que constataram que havia uma correlação forte de 77,7\% entre as informações voluntárias e o tamanho dos relatórios.

Lopes, L. C.; Meira, J. M.; Miranda, L. M.; Vasconcelos, M. T. C.; Santos, A. A. 
A empresa que divulgou os relatórios mais extensos em páginas foi a Centrais Energéticas Brasileiras (Eletrobrás), com 233 páginas. Contudo, foi à quinta empresa que mais divulgou informações da cadeia de valor. Enquanto que a JBS em seu conjunto de relatórios possui apenas 67 páginas, foi à segunda empresa a produzir maior número de sentenças. Contudo, considerando todas as empresas analisadas, pode-se afirmar que quanto maior os relatórios de informações financeiras, maior será o número de divulgação de sentenças relacionadas à Cadeia de Valor. O Gráfico 1 mostra como se comportou a dispersão entre número de páginas nos relatórios e sentenças identificadas neste estudo.

\section{Gráfico 1: Dispersão entre o número de páginas x quantidade de sentenças}

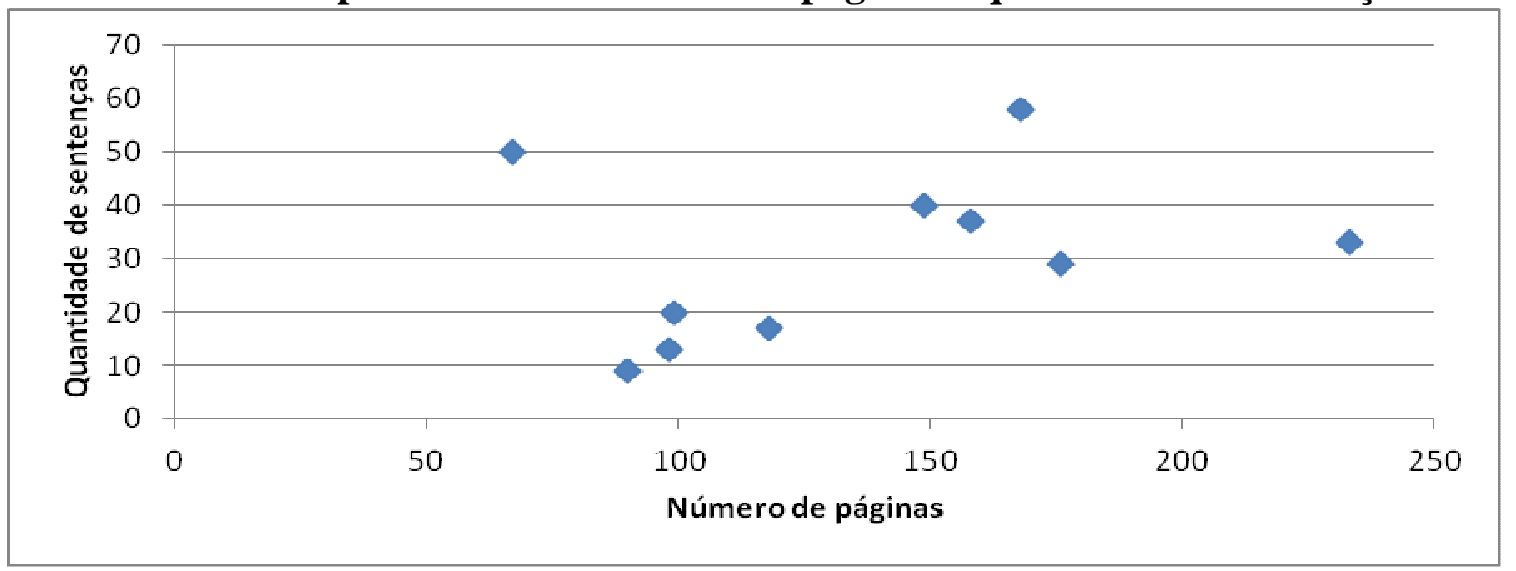

Por último, se verificou se haveria correlação entre a margem bruta obtida pelas empresas no período de análise e as informações divulgadas nos relatórios da administração e notas explicativas, considerando que as empresas que possuíssem maior margem bruta, poderiam ser incentivadas a divulgar informações aos usuários dos relatórios financeiros, demonstrando preocupação com a cadeia de valor e os reflexos em sua margem bruta. As empresas pesquisadas possuem respectivamente as margens brutas no mesmo ano de análise dos relatórios financeiros consultados neste estudo (Quadro 6).

Quadro 6: Margem bruta das empresas analisadas
\begin{tabular}{|l|c|}
\hline \multicolumn{1}{|c|}{ Empresas } & Margem Bruta \\
\hline Centrais Elétricas Brasileiras S.A. - Eletrobrás & 85,74 \\
\hline Companhia de Bebidas das Américas - Ambev & 67,58 \\
\hline Telefônica Brasil S.A. & 50,63 \\
\hline Companhia Siderúrgica Nacional & 40,67 \\
\hline Companhia Energética de Minas Gerais - Cemig & 37,04 \\
\hline Petróleo Brasileiro S.A. - Petrobrás & 31,63 \\
\hline Gerdau S.A. & 14,43 \\
\hline Braskem S.A. & 11,63 \\
\hline JBS S.A. & 10,84 \\
\hline
\end{tabular}

Fonte: Economática (2012)

A empresa que obteve maior margem bruta no período foi a Eletrobrás $(85,74 \%)$, que obteve uma diferença de quase $20 \%$ para a segunda colocada, Ambev. A JBS embora tenha sido a segunda empresa a divulgar o maior número de informações relacionadas à sua cadeia de valor é a que obteve a menor margem bruta no período (Gráfico 2).

Divulgação Voluntária da Cadeia de Valor nos Relatórios Financeiros de Empresas Brasileiras de Capital Aberto 
Gráfico 2: Margem bruta x sentenças identificadas

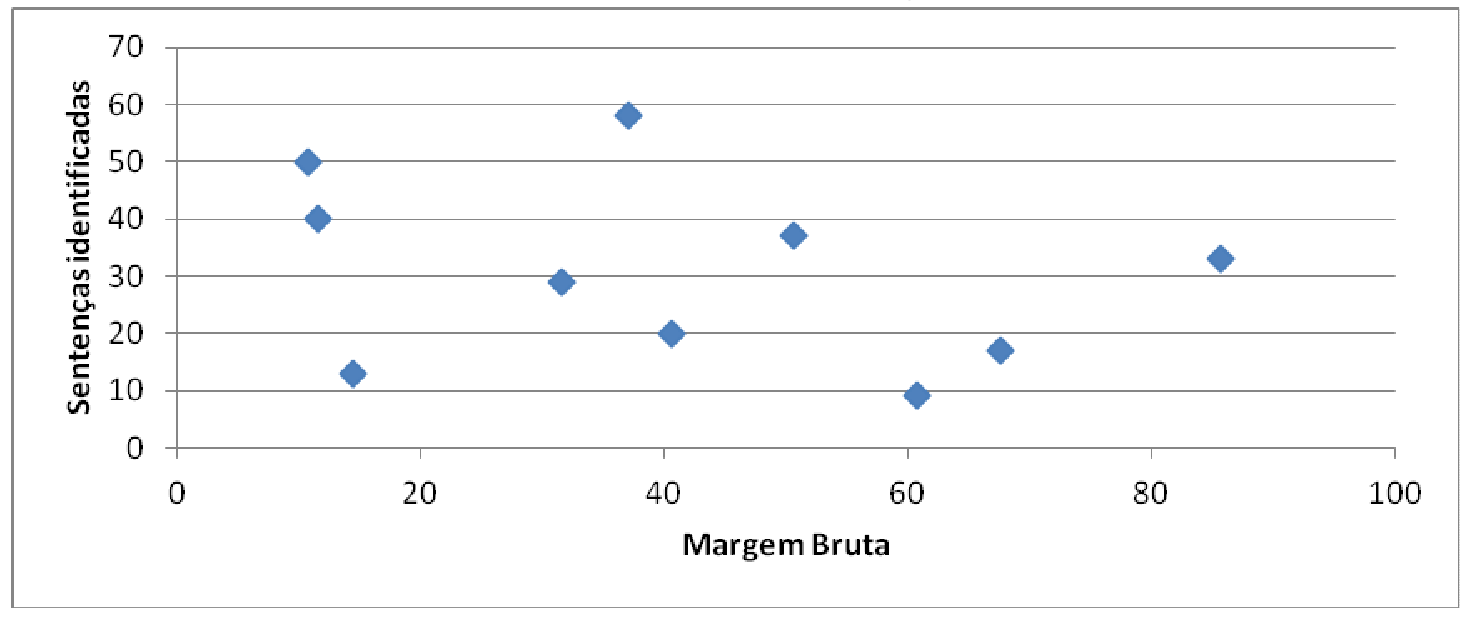

O valor encontrado para verificar correlação entre as duas variáveis propostas no objetivo deste estudo $(-30 \%)$ indica correlação fraca entre elas. O coeficiente de determinação possui baixo poder de explicação quando se busca correlacionar as empresas que possuem margem bruta maior com o volume de sentenças identificadas como divulgação da cadeia de valor. $\mathrm{O} \mathrm{r}^{2}$ calculado foi de apenas 0,90 que pode indicar que estatisticamente à margem bruta maior influencia apenas em 9\% a decisão em divulgar mais informações. Portanto, é possível afirmar que existem outras variáveis capazes de explicar mais fortemente a tendência que representam $91 \%$ dessa influência.

\section{Conclusão}

A divulgação de informações nos relatórios financeiros contribui para que os usuários conheçam os negócios e saibam as características de cada empresa que se pretende investir ou que já possua algum tipo de participação. Por isso, precisa-se ter cuidado em divulgações, principalmente, quando se trata de empresas de capital aberto que negociam seus títulos no mercado de ações que precisam atrair investidores e obter valorização de seu patrimônio.

A análise de conteúdo possibilitou constatar que há interesse das empresas em trazer informações de sua cadeia, principalmente, porque essas divulgações não têm natureza obrigatória, o que permite a empresa fazer o julgamento sobre o volume de informações que deve apresentar, bem como, o que deve mostrar nos seus relatórios.

As empresas selecionadas na amostra obtiveram uma média de 30 sentenças identificadas nos relatórios analisados. A empresa que mais trouxe informações foi a Companhia Energética de Minas Gerais - Cemig, que representou 18,95\% do total com 58 sentenças. Enquanto que a empresa Vale foi a que menos apresentou essas informações.

As atividades desenvolvidas na cadeia de valor interna e externa foram as mais destacadas nos relatórios financeiros das empresas. Enquanto que as subcategorias "Poder de negociação dos fornecedores, Visão de todo o negócio ou visão sistêmica e Ciclo de vida do produto/serviços", obtiveram percentual baixo, pois só foi possível identificar um pequeno volume de sentenças que puderam ser relacionadas com os pontos do modelo metodológico adotado.

Sobre o objetivo deste estudo, foi testado se havia correlação significativa entre o volume da divulgação da cadeia de valor e o tamanho dos relatórios. Semelhante ao achado no estudo realizado por Wrubel, Diehl e Ott (2010), foi encontrado um percentual considerado significativo para esta pesquisa que permitiu essa conclusão.

Lopes, L. C.; Meira, J. M.; Miranda, L. M.; Vasconcelos, M. T. C.; Santos, A. A. 
Foi testado também se havia correlação significativa entre o volume de divulgação de sentenças da cadeia de valor com uma maior margem bruta obtida pela empresa no mesmo período. Constatou-se que não havia correlação significativa que pudesse considerar essa possibilidade verdadeira. Portanto, pode-se dizer que outras variáveis podem melhor explicar a tendência em divulgar essas informações. Os resultados deste estudo podem apenas atribuir com as conclusões encontradas para as empresas que compuseram a amostra, não podendo, portanto, serem generalizadas às demais empresas brasileiras listadas na Bolsa de Valores de São Paulo (Bovespa), pois o número de empresas analisadas foi insuficiente para isso.

Para futuras pesquisas, sugere-se a ampliação da amostra e o período analisado, de forma que seja possível verificar quais setores trazem mais informações, e observar se há uma tendência em aumentar o destaque dado à divulgação das informações da cadeia de valor com o passar dos anos, melhorando assim a comunicação entre a empresa e os seus investidores, credores e outros interessados. Bem como realizar uma pesquisa survey consultando os gestores sobre suas razões para determinar internamente o volume de informações do gerenciamento da cadeia de valor que será divulgado em seus relatórios financeiros anuais.

\section{Referências}

BANDEIRA, Renata Albergaria de Mello; MELLO, Luiz Carlos Brasil de Brito; MAÇADA, Antonio Carlos Gastaud. Relacionamento interorganizacional na cadeia de suprimentos: um estudo de caso na indústria da construção civil. Produção, v. 19, n. 2, p. 376-387, 2009.

BARDIN, Laurence. Análise de conteúdo. Edição revisada e ampliada. São Paulo: Edições 70, 2011.

BRAVO, Francisco; ABAD, Cristina; TROMBETTA, Marco. Methodological and empirical analysis of problems in the measurement of voluntary disclosure. In: European Accounting Association Annual Congress. Rotterdam: 2008, vol. 31.

COLARES, Marcelle; PONTE, Vera Maria Rodrigues. A prática da evidenciação de informações avançadas e não obrigatórias nas demonstrações contábeis das Empresas brasileiras. In: Anais do XXVII ENANPAD 2002. Atibaia: 2003.

COOPER, M. C; LAMBERT, D. M; PAGH, J. D. Supply chain management: more than a new name for logistics. The International Journal of Logistics Management, v. 8, n. 1, p. 1-14, 1997.

CUNHA, Jacqueline Veneroso Alves da; RIBEIRO, Maisa de Souza. Divulgação voluntária de informações de natureza social: um estudo nas empresas brasileiras. Revista de Administração Eletrônica, v. 1, n. 1, art. 6, 2008.

ELMUTI, Dean. The Perceived Impact of Supply Chain Management on Organizational Effectiveness. Journal of Supply Chain Management, v. 38, n. 3, p. 49-57, 2002.

ELMUTI, Dean; MINNIS, William; ABEBE, Michael. Longitudinal assessment of an integrated industrial supply chain. Supply Chain Management: An International Journal, v. 13, n. 2, p. $151-159,2008$. 
HEALY, Paul M; PAPELU, Krishna G. Information asymmetry, corporate disclosure, and the capital markets: A review of the empirical disclosure literature. Journal of Accounting and Economics, v. 31, p. 405-440, 2001.

HENDRIKSEN, Eldon S; BREDA, Michael F. Van. Teoria da Contabilidade. 5 ed. São Paulo: Atlas, 1999.

LI, S.; CHEN, F. Measuring the Performance of Integrated Supply Chain Management. Proceedings, Midwest Business Administration Association, P\&O Track, Chicago, IL, v. 9, p. 9-14, 2001.

MEIRA, Juliana Matos de. Supply chain management and inter-organisational accounting a brasilian case. Tese de Doutorado. The University of Sheffield, UK: April, 2011.

MENTZER, J. T; DEWITT, W; KEEBLER, J. S. et al. Defining supply chain management. Journal of Business Logistics, v. 22, n. 2, p. 1-25, 2001.

MURCIA, Fernando Dal-Ri; SANTOS, Ariovaldo dos. Fatores determinantes do nível de disclosure voluntário das companhias abertas no Brasil. REPeC - Revista de Educação e Pesquisa em Contabilidade, v. 3, n. 2, art. 4, p. 72-95, 2009.

PORTER, Michael E. Vantagem Competitiva: criando e sustentando um desempenho superior. Trad. Elizabeth Maria de Pinho Braga. Rio de Janeiro: Campus, 1989.

ROCHA, Wellington; BORINELLI, Marcio Luiz. Análise Estratégica da Cadeia de Valor: um estudo exploratório do segmento indústria-varejo. Revista Contemporânea de Contabilidade, ano 4, vol. 1, nº 7, p. 145-165, 2007.

SHANK, J. K.; GOVINDARAJAN, V. A Revolução dos Custos: como reinventar e redefinir sua estratégia de custos para vencer em mercados crescentemente competitivos. Trad. Luiz Orlando Coutinho Lemos. $2^{\mathrm{a}}$ ed. Rio de Janeiro: Campus, 1997.

WRUBEL, Franciele; DIEHL, Carlos Alberto; OTT, Ernani. Informações sobre gestão estratégica de custos divulgadas por companhias abertas brasileiras. Revista Contemporânea de Contabilidade, ano 07, v.1, n¹3, p. 127-150, 2010. 